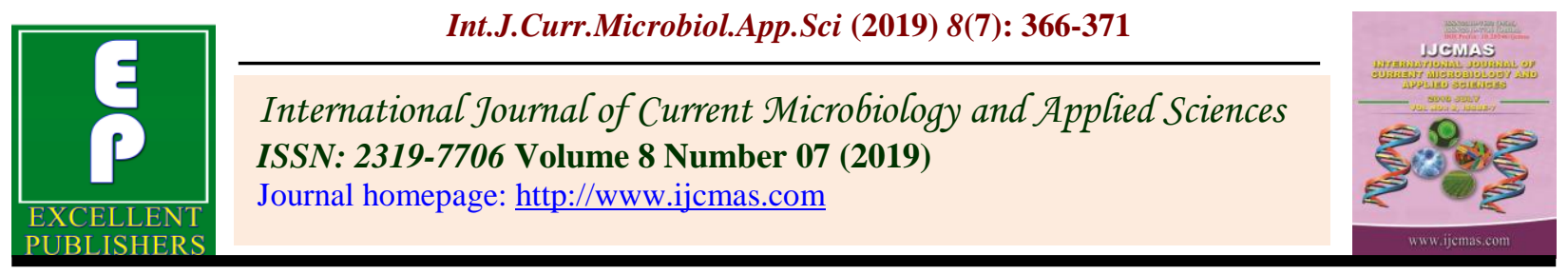

Original Research Article

https://doi.org/10.20546/ijcmas.2019.807.045

\title{
Study on Behavioural Problems among Tribal Children Attending Anganwadis in Adilabad District of Telangana, India
}

\author{
J. Navitha ${ }^{1 *}$, P. Sreedevi ${ }^{1}$, M. Sarada Devi ${ }^{1}$ and S.L. Kameswari ${ }^{2}$ \\ ${ }^{1}$ Department of Human Development and Family studies, College of Home Science, \\ Hyderabad, Telangana, India \\ ${ }^{2}$ Department of Home science Extension and Communication Management, College of Home \\ Science, Hyderabad, Telangana, India \\ *Corresponding author
}

\begin{abstract}
A B S T R A C T
\end{abstract}
Keywords

Behavioural problems, Tribal children behavioural problems, Anganwadi children, Correlates of behavioural problems

\section{Article Info}

Accepted:

04 June 2019 Available Online: 10 July 2019
The present research study was undertaken to study the Behavioural problems of tribal children attending Anganwadis. A sample of 180 children in the age range of 3-6 years who were attending Anganwadi centers in Adilabad district of Telangana were selected by purposive random sampling method. Ex-post facto research design was opted for the study. Preschool Behaviour questionnaire was used for study the children behavioural Problems. Frequencies and Percentages were used to analyze the data. The findings revealed that majority of tribal children from 3-6 years had low behavioural problems, very few of them had moderate level and meager percentage had high level behavioural problems in all three dimensions i.e. hostile- aggressive, Anxious- Fear and Hyperactivity and distractibility. Boys showed high level hostile- aggressive behaviours than girls, whereas girls showed the AnxiousFear behaviours than boys. Parental age and education, family type had significant negative correlation with behavioural problems of children. Children of younger age parents, illiterate parents and nuclear families exhibited more behavioural problems.

\section{Introduction}

Tribal population were most neglected and oppressed groups in India, The Integrated Child Development Services (ICDS) are the largest and most unique outreach programmes for early childhood care and development in India. It provides an opportunity for the holistic development of children from vulnerable backgrounds. Early childhood, is a critical period where the growth and development takes place in all the areas of development. Physical changes in early childhood are occurred by rapid changes in the child's socio-emotional, cognitive and language development. It was found that some 
preschool children show difficult behaviors, so identifying and helping these children is a vital task. Lack of appropriate help and support for emotional difficulties that emerges in early years of life can become more serious disorders over time. Researchers are finding that intervening at this time in life can be highly effective in helping children develop better coping skills. Hence an attempt was made to study the Behavioural problems among the tribal children attending Anganwadis.

\section{Objectives}

To study the Demographic profile of tribal children attending Anganwadis.

To study the Behavioural problems among the tribal children attending Anganwadis

To study the association between demographic factors and Behavioural problems

\section{Materials and Methods}

Based upon the nature of the research problem and objectives of the present study, Ex-post facto research design was used for the study. The sample was selected from 30 Tribal Anganwadi centers Adilabad district, Telangana. The sample comprises of 180 in the age range of 3-6 years includes 90 boys from 30 Anganwadi centers and 90 girls from 30 Anganwadi centers. A schedule was designed to collect general profile of children and Preschool Behavioural questionnaire by Lenore B. Behar used to collect the data. The questionnaire was categorized into three dimensions such as Hostile- Aggressive, Anxious-Fear and HyperactivityDistractibility. Scoring procedure for Does not applies (0), Applies Sometimes (1), certainly Applies (2) respectively. Frequencies, percentages and Correlation were used to analyze the data.

\section{Results and Discussion}

From table 1 it was clearly observed that, less than half of children were in the age range of 3-4 years, followed by 4-5 years and only few of them were in 5-6 years. With regards to their birth order, more than one third were first borns, followed by second borns and third borns and a very few were fourth, fifth and sixth borns. An equal number of boys and girls were selected for the study comprising of fifty percent for both the genders. More than half of the children were belonged to nuclear families followed by joint families and none of them were from extended families.

Considering the income levels, almost all of the families belonged to low income groups and agriculture followed by wage labour were their main occupations. Similar results were found Behera (2016), who found that primitive tribal communities were lagging behind than the normal population with respect to their income. Gopika (2018) also revealed that, agriculture is the main occupation among scheduled tribes and agriculture sector provides them with the main means of livelihood.

With regard to age of the parents, less than half of the parents were in the age range of 2530 years followed by 20-25 years. Few were in the age range of 30-35 years followed by $35-40$ years. With regard to the parental education, forty percent of mothers and fathers had primary education. Forty percent of the mothers were illiterates it was $24 \%$ among fathers. Few parents had secondary education and meager percentage of parents had intermediate and above.

The above graph clearly depicts about the status of behavioural Problems among the tribal children attending Anganwadis. It was observed that most of the children had low behaviuoral problems, very few had moderate 
level and meager percent had high behaviuoral problems in all the three dimensions i.e. Hostile- Aggressive, Anxious-Fear, Hyperactivity- Distractibility.

Hostile- Aggressive behaviours were observed more among tribal children attending Anganwadis when compared to Anxious-Fear and Hyperactivity- Distractibility behaviours.

Children with moderate level Hostileaggressive problems (25\%) involved occasionally in fighting, kicking, biting, hitting other children exhibited fights with the other children. They were not considerate about other children and does not willing to share, blame others, tells lies and destroy others properties.

Children with moderate level anxious-fear problems were occasionally fearful towards others, cries easily and gives up easily. Children with Hyperactivity- distractibility problems exhibited behaviours like poor concentration, inattention and irritability. This might due to imitation of quarrelling behaiours at home and also parental neglect. Similarly, the study conducted by Kulkarni(2014) reported that more than one third (38.4\%) percent don't know the exact reasons for their child's behavioural problems and one third of them said parental quarrelling was a major reason and nearly one fifth of them expressed parental neglect as major reason.

Meager percentage had high level behavior problems in the dimensions of HostileAggressive and Anxious -Fear and none of them were high in hyperactivity-Distractibility dimension. The results were supported by Rishika Agarwal (2018) who reported that most $(90 \%)$ of the tribal children were had low behaviour problem, 10 percent were in moderate level and none of them were had high behavioural problems. One more study by Kumari Poonam (2018) reported that most (79\%) of the Anganwadi children not had behavioural problems and only few (21\%) children had behavioural problems (Fig. 1).

Fig.1 Behavioral Problems of tribal children attending Angawadis

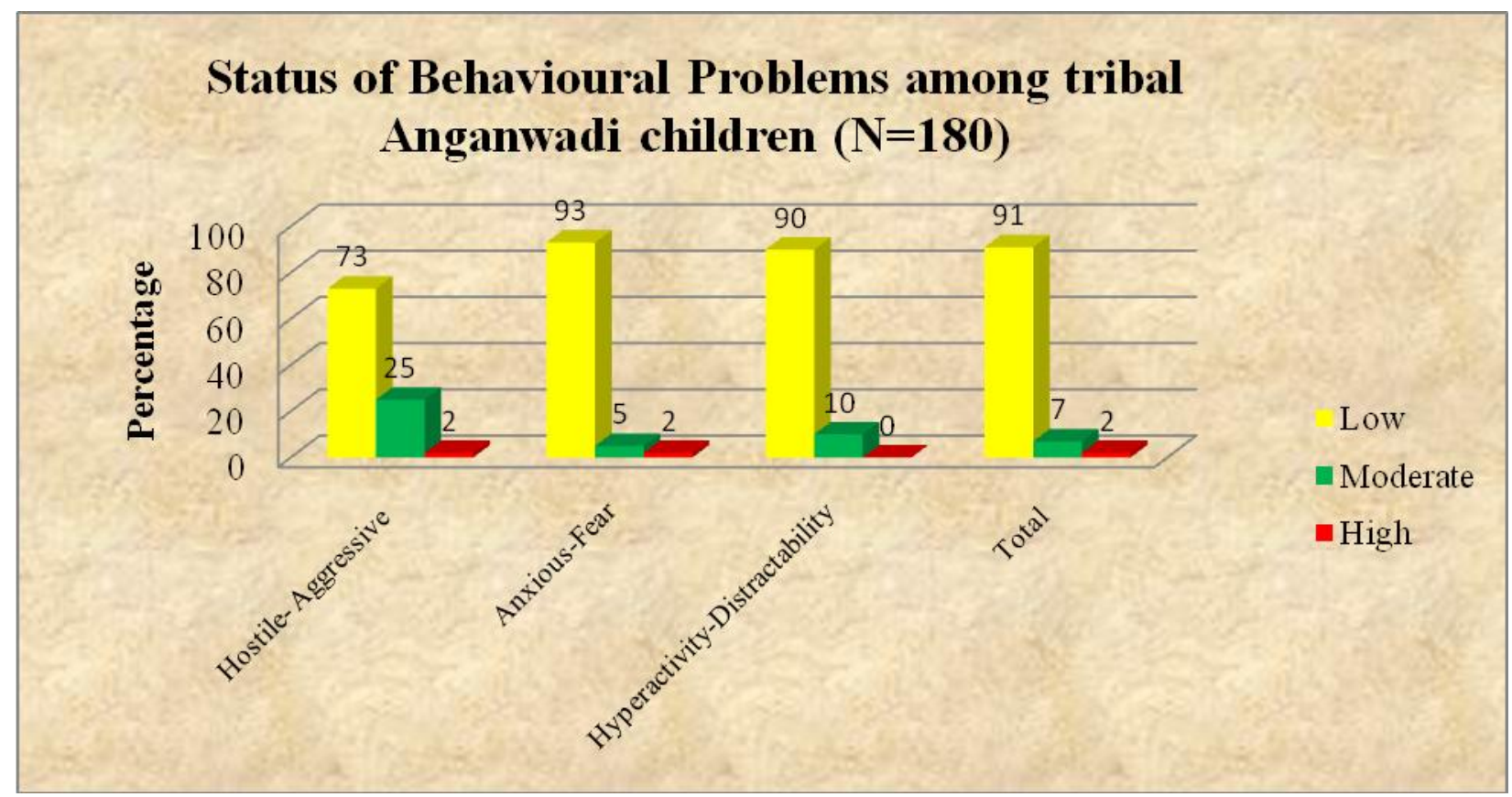


Table.1 Demographic profile of tribal children attending Anganwadis

\begin{tabular}{|c|c|c|c|}
\hline Sl. No & Variable & Frequency $\mathbf{N}$ & Percentage (\%) \\
\hline \multirow[t]{4}{*}{1} & \multicolumn{3}{|l|}{ Age } \\
\hline & 3-4 years & 76 & $42 \%$ \\
\hline & $4-5$ years & 78 & $44 \%$ \\
\hline & 5-6 years & 26 & $14 \%$ \\
\hline \multirow[t]{3}{*}{2} & \multicolumn{3}{|l|}{ Gender } \\
\hline & Boys & 90 & $50 \%$ \\
\hline & Girls & 90 & $50 \%$ \\
\hline \multirow[t]{7}{*}{3} & \multicolumn{3}{|l|}{ Birth order } \\
\hline & $1^{\text {st }}$ born & 72 & $40 \%$ \\
\hline & $2^{\text {nd }}$ born & 47 & $26 \%$ \\
\hline & $3^{\text {rd }}$ born & 40 & $22 \%$ \\
\hline & $4^{\text {th }}$ born & 12 & $7 \%$ \\
\hline & $5^{\text {th }}$ born & 7 & $4 \%$ \\
\hline & $6^{\text {th }}$ born & 2 & $1 \%$ \\
\hline \multirow[t]{4}{*}{4} & \multicolumn{3}{|l|}{ Income levels } \\
\hline & Low & 179 & $99 \%$ \\
\hline & Average & 1 & $1 \%$ \\
\hline & High & -- & -- \\
\hline \multirow[t]{4}{*}{5} & \multicolumn{3}{|l|}{ Family Type } \\
\hline & Joint & 79 & $44 \%$ \\
\hline & Nuclear & 101 & $56 \%$ \\
\hline & Extended & 0 & $0 \%$ \\
\hline \multirow[t]{5}{*}{6} & \multicolumn{3}{|l|}{ Father Age } \\
\hline & 20-25 years & 48 & $27 \%$ \\
\hline & 25-30 years & 77 & $43 \%$ \\
\hline & $30-35$ years & 29 & $16 \%$ \\
\hline & $35-40$ years & 26 & $14 \%$ \\
\hline \multirow[t]{5}{*}{7} & \multicolumn{3}{|l|}{ Mother Age } \\
\hline & $20-25$ years & 66 & $36 \%$ \\
\hline & $25-30$ years & 84 & $47 \%$ \\
\hline & $30-35$ years & 27 & $15 \%$ \\
\hline & $35-40$ years & 3 & $2 \%$ \\
\hline \multirow[t]{7}{*}{8} & Father Education & & \\
\hline & Illiterate & 44 & $24.4 \%$ \\
\hline & Primary Education & 70 & $40 \%$ \\
\hline & Secondary Education & 48 & $26 \%$ \\
\hline & Intermediate & 15 & $8 \%$ \\
\hline & Degree & 2 & $1.1 \%$ \\
\hline & Post graduation & 1 & $0.5 \%$ \\
\hline \multirow[t]{7}{*}{9} & \multicolumn{3}{|l|}{ Mother Education } \\
\hline & Illiterate & 71 & $40 \%$ \\
\hline & Primary Education & 74 & $41 \%$ \\
\hline & Secondary Education & 22 & $12 \%$ \\
\hline & Intermediate & 11 & $6 \%$ \\
\hline & Degree & 1 & $0.5 \%$ \\
\hline & Post graduation & 1 & $0.5 \%$ \\
\hline \multirow[t]{6}{*}{10} & \multicolumn{3}{|l|}{ Father occupation } \\
\hline & Farmer & 144 & $80 \%$ \\
\hline & Auto Driver & 6 & $3 \%$ \\
\hline & Kuli (labour work) & 28 & $16 \%$ \\
\hline & Tailor & 1 & $0.5 \%$ \\
\hline & Teacher & 1 & $0.5 \%$ \\
\hline
\end{tabular}


Table.2 Relationship between the selected independent variables with dependent variable i.e. Behavioural problems

\begin{tabular}{|l|c|c|c|c|}
\hline Variables & $\begin{array}{c}\text { Hostile- } \\
\text { Aggressive }\end{array}$ & $\begin{array}{c}\text { Anxious- } \\
\text { Fear }\end{array}$ & $\begin{array}{c}\text { Hyperactivity- } \\
\text { Distractibility }\end{array}$ & Total \\
\hline Child Age & $.025 \mathrm{NS}$ & $-.032 \mathrm{NS}$ & $.030 \mathrm{NS}$ & $-.010 \mathrm{NS}$ \\
\hline Gender & $-.198^{* *}$ & $.328^{* *}$ & $.130 \mathrm{NS}$ & $.014 \mathrm{NS}$ \\
\hline Birth order & $.048 \mathrm{NS}$ & $-.028 \mathrm{NS}$ & $.011 \mathrm{NS}$ & $.063 \mathrm{NS}$ \\
\hline Father's Age & $-.163^{*}$ & $.016 \mathrm{NS}$ & $-.093 \mathrm{NS}$ & $-.034 \mathrm{NS}$ \\
\hline Mother's Age & $-.184^{*}$ & $-.027 \mathrm{NS}$ & $-.121 \mathrm{NS}$ & $-.034 \mathrm{NS}$ \\
\hline Father's Education & $-.109 \mathrm{NS}$ & $.022 \mathrm{NS}$ & $-.111 \mathrm{NS}$ & $-.327^{* * *}$ \\
\hline Mother's Education & $-.238^{* *}$ & $-.096 \mathrm{NS}$ & $-.236^{* *}$ & $-.273^{* *}$ \\
\hline Income levels & $-.016 \mathrm{NS}$ & $-.017 \mathrm{NS}$ & $-.024 \mathrm{NS}$ & $-.015 \mathrm{NS}$ \\
\hline Family Type & $.023 \mathrm{NS}$ & $-.136 \mathrm{NS}$ & $-.087 \mathrm{NS}$ & $-.159^{*}$ \\
\hline
\end{tabular}

The children who scored high in all these three dimensions exhibited more speech difficulties like stuttering and stammering, and disruptive behavioural problems like inattention and poor concentration and temper tantrums like biting, hitting others etc.

Children who had high behavioural problems had a chances to prevalent of the risk behaviours in further development or later development.

The table 2 clearly explained about relationship between the selected independent variables and behavioural Problems. It was found that education of both father and mother was significantly negatively correlated with child's behavioural problems at 01 level. Which means that as the parent education increases behaviour problems of the child decreases. This might be due to the reason that educated parents modeled good behaviours and were able to identify and manage their child's behaviours than illiterate parents.

The above results supported by Kulkarni (2014) who found that Maternal education was significantly associated with behavioral problems in children, prevalence being highest in offspring's of illiterate mothers and nuclear family children had more behavioural problems.

Family type had significantly and negatively correlated with behavioural problems of the child at.05 level. Which indicates that children from nuclear families exhibited high behavioural problems when compared to joint families. This might be due to the fact that the child's behavior is checked, regulated, monitored and handled the situations and gave the advices to the children by different adults in joint families where as this motoring and control is less in nuclear families.

Parental age had significant negative relationship with Hostile-Aggressive and Hyperactivity-Distractibility and Behaviuoral problems at. 05 level. Which means as parental age increases hostile and hyperactive behaviors decreases. Experienced parents were more mature in managing and controlling their child's behaviours than less experienced parents.

Gender has significant positive relationship with Anxious - fear and negative relationship with Hostile-Aggressive behaviours of children. Which indicates that girls had more Anxious - Fear behavious when compared to the boys. Boys had more Hostile- Aggressive 
behaviours when compared to the girls. Reddy et al., (2016) reported that in preschool children particularly boys had temper tantrums, fights and bites, destructive nature, management problems, hyperkinesis and distractibility more when compared to girls.

The study concludes that behavioural problems existed at low level among most of the tribal children attending anganwadis. It is important to note that few of them had at moderate level and meager percent had them at high level. Hostile- Aggressive behaviours are more when compared to the anxious and fear, hyperactive and distractive behavious. Behaviour problems decreases with parental age, parental education and family type. Children of illiterate parents, younger age parents and from nuclear families had more behavior problems. Boys had more hostile and aggressive behaviours than girls whereas girls had more fear and anxious behviours than boys.

Thus, the present study suggest effective parent education programmes for both younger parents and illiterate parents in order to improve their parenting skills in how to handle and reduce the behaviuoral problems in their children and how to inculcate positive behaviours in the children. Anganwadi teacher should be trained in early identification and management of behavioural problems in children and also to guide and counsel the parents.

\section{References}

Agarwal R, Yadav SK, Nijhawan A, Nijhawan M, Preetkamal. A Comparative Study of Behaviour Problems in Tribal and Nontribal Children Residing In Urban Areas. Journal of Dental and Medical Sciences, 2018; 17(2): 22-29.

Behera M. Income and Expenditure of Particularly Vulnerable Tribal Groups of Odisha: A comparative Analysis. Journal of Economic \& Social Development, 2016; Vol-12: 146-154.

Gopika GG. Socio-Economic Study of Kani Tribe in Trivandrum: A Case study of Njaraneeli Settlement. 2018; Thesis.

Kulkarni SS, Kumavat AP, Dixit JV. Behavioral Problems among Preschool children: A Descriptive Study at Solapur. National Journal of Research in Community Medicine, 2014; 3(2): 113-117.

Reddy BRN, Pawar JM, Anudhakar CD, Mishra L and Goyal R. Study of behavior problems in preschool children. Journal of Medical science and Clinical Research, 2016; 2(12): 1464114649

\section{How to cite this article:}

Navitha, J., P. Sreedevi, M. Sarada Devi and Kameswari, S.L. 2019. Study on Behavioural Problems among Tribal Children Attending Anganwadis in Adilabad District of Telangana, India. Int.J.Curr.Microbiol.App.Sci. 8(07): 366-371.

doi: https://doi.org/10.20546/ijcmas.2019.807.045 